\title{
Study of frost resistance of generative buds of scion/ rootstock combinations of sweet cherry by freezing in controlled conditions
}

\author{
G.Yu. Upadysheva*, S.M. Motyleva, T.A. Tumaeva, M.E. Mertvischeva, and M.T. \\ Upadyshev
}

FSBSI "Federal Horticultural Research Center for Breeding, Agrotechnology and Nursery", Moscow, Russia

\begin{abstract}
The paper presents the results of two-year research on frost resistance study in 18 scion/rootstock combinations of sweet cherry: Fatezh and Chermashnaya varieties grafted on 9 rootstocks (Izmailovsky, AVCH-2, V-5-88, VC-13, Moskoviya, VSL-2, Stepnoy Rodnik, Colt and seedling rootstock Prunus magaleb L.). The research was carried out in 2019-2020 in the laboratory of physiology and biochemistry of FSBSI «Federal Horticultural Research Center for Breeding, Agrotechnology and Nursery» by artificial freezing method in the climate chamber TH-6 JEIO TECH -1000. It was established that after freezing at $\mathrm{t}=-29^{\circ} \mathrm{C}$, the floral rudiments' preservation in the Fatezh variety was more than $80 \%$, and in the Chermashnaya variety - about $40 \%$. Limits of frost resistance change of varieties' reproductive buds depending on the rootstock were shown: Fatezh variety - from $62.2 \%$ (VSL-2) to $81.7 \%$ (Izmailovsky), and Chermashnaya variety - from $25.5 \%$ (P. magaleb L) to $65 \%$ (Izmailovsky). When using Izmailovsky and AVCH-2 clone rootstock, the preservation of flower rudiments increased by $15-20 \%$ compared to $\mathrm{P}$. magaleb L. The most frost-resistant scion/rootstock combinations were revealed: Fatezh/Izmailovsky and Fatezh/AVCH-2, which preserved more than $87 \%$ of live rudiments. A positive correlation between floral buds' frost resistance and chlorogenic acid content has been established.
\end{abstract}

\section{Introduction}

Successful sweet cherry cultivation in the middle horticulture zone of Russia is limited by its insufficient resistance to frosts in winter. Not only introduced varieties, but also varieties bred specifically for the northern regions are periodically damaged by critical frosts here [1-3]. When the air temperature decreases to $-28-30{ }^{\circ} \mathrm{C}$ in abnormally cold winters, sweet cherry's reproductive buds get damaged first, which leads to a flowering deterioration and a decrease in productivity $[4,5]$. Floral buds' frost resistance of stone fruit crops' varieties can vary significantly depending on the rootstock used $[6,7]$. The rootstock affects the end of shoots growth and the course of physiological and biochemical processes in the autumn period that determine the level of sweet cherry's adaptability to adverse

\footnotetext{
* Corresponding author: upad64@mail.ru
} 
factors [8]. Artificial frosting works of scion/rootstock combinations of sweet cherries and plums showed an increase in winter resistance of buds and tissues under the influence of some clone rootstock of domestic breeding [9, 10]. At the same time, in the middle horticulture zone of the Russian Federation, there are very few studies on the rootstock influence on the sweet cherry winter resistance level [11]. The adaptation mechanism of fruit plants to low-temperature stress is closely related to biochemical processes and depends on the synthesis of certain chemical substances. The potential winter resistance of reproductive and vegetative plants' parts can be judged by the change in the content of combined and free water and proline amino acid in annual branches, dry matter dynamics and reductive sugars, etc. $[12,13]$. Phenolcarboxylic acids and, above all, chlorogenic acid play a significant role in the formation of protective plants' action on winter period stressors [14].

The purpose of our research was to study the influence of clone rootstock on the frost resistance of sweet cherry's reproductive buds and the selection of the most frost-resistant scion/rootstock sweet cherry combinations.

\section{Materials and methods}

The research was carried out in 2019 - 2020 in the laboratory of physiology and biochemistry of FSBSI «Federal Horticultural Research Center for Breeding, Agrotechnology and Nursery» by artificial freezing in laboratory conditions. Frost resistance was studied in 2 sweet cherry varieties (Fatezh, Chermashnaya) grafted on 8 clone rootstocks (Izmailovsky, AVCH-2, V-5-88, VC-13, Moskoviya, VSL-2, Stepnoy Rodnik, Colt) and seedling rootstock of Prunus magaleb L. (control). A total of 18 scion/rootstock combinations were under study. The age of trees - 12-13 years. Every year, damaging low-temperature effects of the II component were simulated in laboratory conditions, revealing maximum frost resistance to critical frosts in the conditioned state. Experiments' establishment and damage assessment was carried out according to the methodology [15].

Two-year branches with fruit formations and annual growth were prepared for freezing in early December after stable negative temperatures onset, labelled and stored in the refrigerated cabinet POLAIR (WH-0.7) at $\mathrm{t}=-2{ }^{\circ} \mathrm{C}$. Each option included 10 branches. Before freezing, the branches were conditioned for 5 days at $\mathrm{t}=-5^{\circ} \mathrm{C}, 5$ days at $\mathrm{t}=-10^{\circ} \mathrm{C}$ and then frosted in the climatic chamber TH-6 JEIO TECH -1000 at $\mathrm{t}=-2{ }^{\circ} \mathrm{C}$. The damage degree to reproductive buds was assessed after growing by determining the proportion of living floral rudiments in $\%$ of their total number. At the same time, the reproductive buds' damage on annual growth and on bouquet branches was assessed separately.

The material for biochemical research was the buds of the studied sweet cherry scion/rootstock combinations. Chlorogenic acid content was determined before and after freezing by HPLC method using KNAUER liquid chromatograph according to GOST P54684-2011. Experimental data were processed by dispersion and correlation analyses using the Statistica 6.0 computer program.

\section{Results and discussion}

Experimental two-year data analysis showed that in mid-winter after conditioning, temperature $\mathrm{T}=-29^{\circ} \mathrm{C}$ caused damage to reproductive buds in the studied sweet cherry varieties. More severe reproductive buds damage was noted in the Chermashnaya variety. Under the influence of this temperature, Chermashnaya/Izmailovsky and 
Chermashnaya/AVCH-2 combinations lost less than $41 \%$ and $48 \%$ of flower rudiments respectively, and in combinations of this variety with other rootstock freezing of more than $60 \%$ of floral rudiments was observed. Maximum damage was observed on rootstocks V-588 and Prunus magaleb L. (Table 1).

Table 1. Preservation of floral rudiments in various sweet cherry scion/rootstock combinations with artificial freezing after conditioning in January (II component, $\mathrm{t}=-29{ }^{\circ} \mathrm{C}$ ), \%, 2019-2020

\begin{tabular}{|c|c|c|c|}
\hline \multirow{2}{*}{ Rootstocks } & \multicolumn{2}{|c|}{ Varieties } & \multirow{2}{*}{$\begin{array}{c}\text { average } \\
\text { (factor A) }\end{array}$} \\
\cline { 2 - 3 } & Fatezh & Chermashnaya & $59.5 \mathrm{bc}$ \\
\hline VSL-2 & $78.6 \mathrm{ef} *$ & $40.4 \mathrm{~b}$ & $52.1 \mathrm{ab}$ \\
\hline V-5-88 & $78.7 \mathrm{ef}$ & $25.5 \mathrm{a}$ & $73.5 \mathrm{~d}$ \\
\hline Izmailovsky & $88.2 \mathrm{~h}$ & $58.8 \mathrm{~d}$ & $62.2 \mathrm{c}$ \\
\hline Moskoviya & $85.5 \mathrm{~h}$ & $38.9 \mathrm{~b}$ & $69.8 \mathrm{~d}$ \\
\hline AVCH-2 & $87.8 \mathrm{~h}$ & $51.8 \mathrm{c}$ & $57.5 \mathrm{bc}$ \\
\hline VC-13 & $84.5 \mathrm{gh}$ & $30.4 \mathrm{a}$ & $62.2 \mathrm{c}$ \\
\hline Stepnoy Rodnik & $84.3 \mathrm{gh}$ & $40 \mathrm{~b}$ & $60.8 \mathrm{bc}$ \\
\hline Colt & $80.6 \mathrm{fg}$ & $41.0 \mathrm{~b}$ & $50.1 \mathrm{a}$ \\
\hline $\begin{array}{c}\text { Seedling roostock } \\
\text { Prunus magaleb L. }\end{array}$ & $74.7 \mathrm{e}$ & $28.2 \mathrm{a}$ & \\
\hline $\begin{array}{c}\text { average } \\
\text { factor B) }\end{array}$ & $82.5 \mathrm{~b}$ & $39.7 \mathrm{a}$ & \\
\hline
\end{tabular}

*The same letters indicate values that do not differ significantly with each other at $5 \%$ significance level.

Fatezh variety reproductive buds had significantly greater frost resistance. This variety grafted on clone rootstocks Izmailovsky, AVCH-2, VC-13, Moskoviya and Stepnoy Rodnik preserved over $80 \%$ of live rudiments. Retaining about $70 \%$ of the live floral rudiments, combinations of this variety with rootstock V-5-88, P. magaleb L. and VSL-2 were less resistant to low temperature impact.

The obtained data on increasing reproductive buds' frost resistance of the studied cherry varieties in combinations with the most winter-resistant rootstocks (Izmailovsky, AVCH-2) confirm information available in the scientific literature on the adaptive rootstock influence on scion resistance increase under the abiotic stressors action [16].

The damage degree to reproductive buds depended not only on the variety and rootstock, but also on the conditions of the year. In 2019, the floral rudiments preservation in Fatezh variety on rootstocks' average at $90 \%$ level was noted, in Chermashnaya variety - about 37\%. In 2020, the same freezing mode caused a damage increase in the Fatezh variety and the differences due to the rootstock were more significant. Depending on the rootstock, the proportion of living rudiments in this variety ranged from $62.2 \%$ (VSL-2) to $81.7 \%$ (Izmailovsky). In the Chermashnaya variety, the damage level (about 40\%) and differences in rootstock were preserved, and the fluctuations span depending on the rootstock was from $25.5 \%$ ( $P$. magaleb L.) to 65\% (Izmailovsky). We associate the differences in buds freezing by year both with unfavorable conditions of conditioning course in the autumn period and with a higher crop load in trees of the Fatezh variety in 2019 compared to 2018, which impaired this variety's trees preparation for winter [17].

Reproductive buds at annual growth proved more sensitive to frost action than buds formed on two-year bouquet branches. Bouquet branches of Fatezh variety preserved about $80 \%$ of viable rudiments, on annual growth $-68 \%$, and Chermashnaya variety, $-53 \%$ and $31 \%$ respectively. The greatest differences (up to 20-28\%) in buds' frost resistance on annual and two-year fruit formations were noted when grafted on the rootstocks of Moskoviya, VC-13, Stepnoy Rodnik. At the same time, the same rootstock influence type 
on frost resistance of reproductive buds on bouquet branches and annual growth was noted (Figure 1).

A

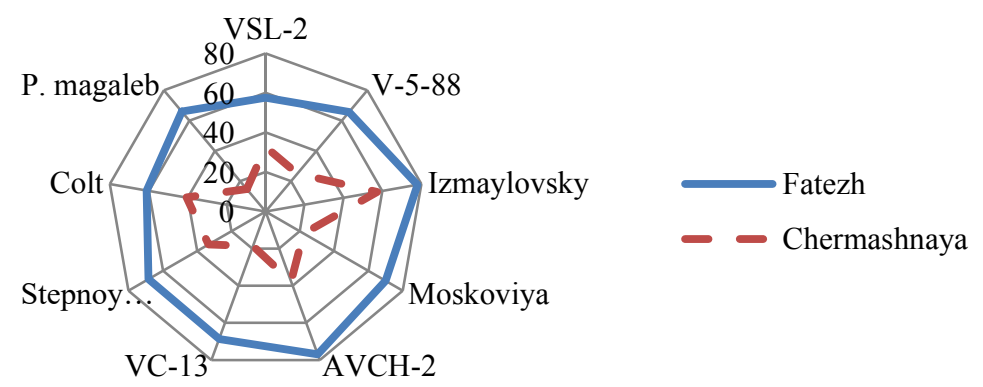

B

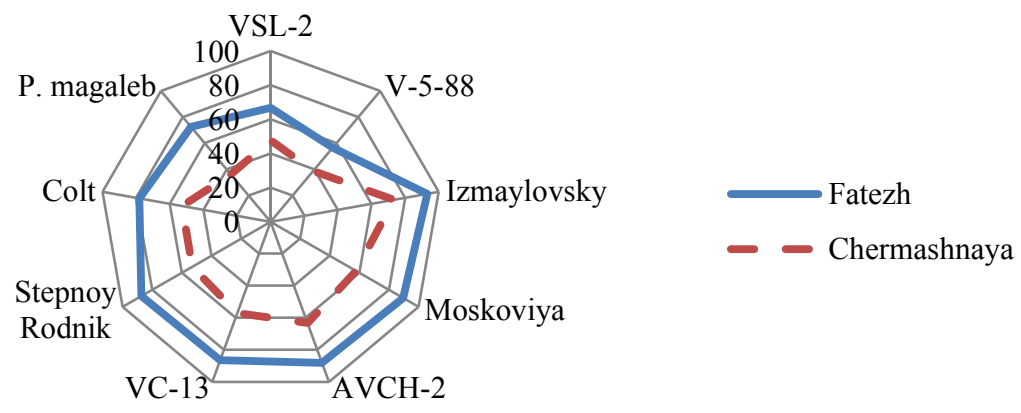

$\mathrm{C}$

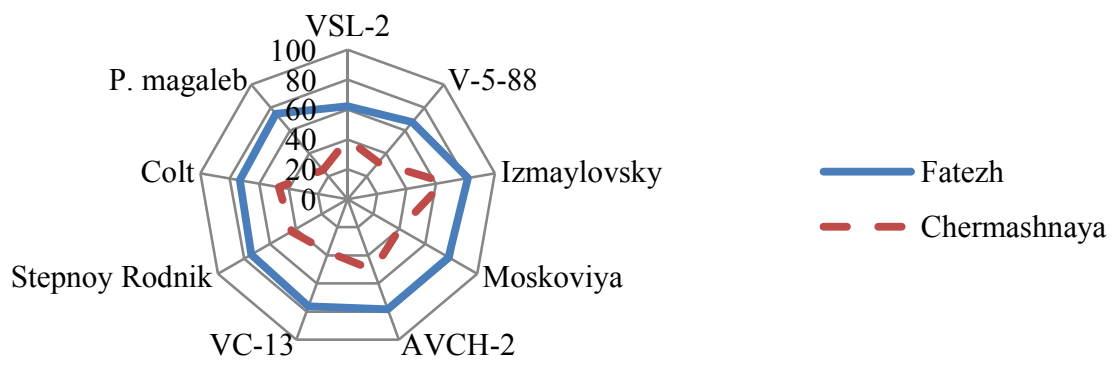

Fig. 1. Preservation of living flower buds in various scion-rootstock combinations of sweet cherries during artificial freezing in January (II component, $\mathrm{t}=-29 \mathrm{C}$ ), $\%, 2020$

Where: A - on annual growth; B - on bouquet branches; C-on average on two-year branches

As a result of biochemical research, it was found that a functionally significant amount of chlorogenic acid was accumulated in sweet cherry buds, which was significantly dependent on the scion/rootstock combination. Prior to freezing, the content of chlorogenic 
acid in sweet cherry buds varied in the range: from $1.99 \mathrm{mg} / \mathrm{g}$ (Chermashnaya/ P.magaleb) to $3.33 \mathrm{mg} / \mathrm{g}$ (Fatezh/Izmailovsky) (Fig. 2).

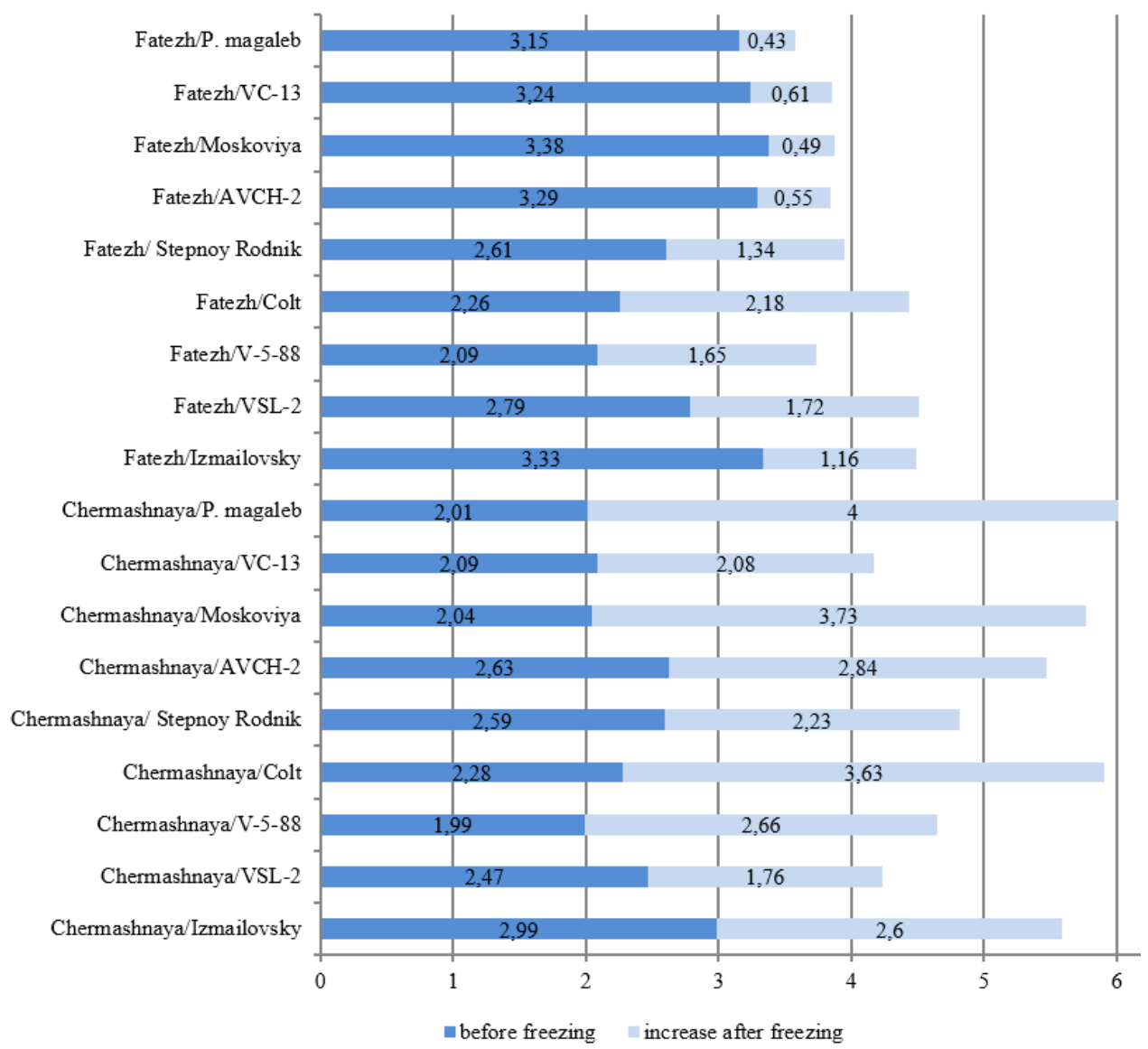

Fig. 2. Content of chlorogenic acid in sweet cherry buds depending on the scion-rootstock combination before and after freezing, $\mathrm{mg} / \mathrm{g}$ of raw mass

The highest chlorogenic acid content was found in the buds of the studied sweet cherry varieties grafted on Izmailovsky, AVCH-2 and Moskoviya rootstocks. With grafting on most rootstocks, Fatezh variety indicators were much higher than those of the Chermashnaya variety. A similar effect of the scion/rootstock combination on the chlorogenic acid content was established earlier in our study of biochemical composition of sweet cherry leaves [17]. Correlation analysis showed the presence of a positive strong connection between the chlorogenic acid content in sweet cherry buds prior to freezing and living floral rudiments preservation $(r=0.75)$, which allows us to consider this indicator a winter resistance marker of sweet cherries' combinations. Our results confirm the conclusions of scientists on the role of chlorogenic acid in the winter resistance assessment of grapes [18].

After freezing, an increase in chlorogenic acid content in all samples was noted, as well as variation depending on the combination from 3.58 to $6.09 \mathrm{mg} / \mathrm{g}$. In the winter-resistant Fatezh variety, this indicator increased by 1.3-1.9 times, and in less winter-resistant combinations (Chermashnaya/P.magaleb, Chermashnaya/Colt, Chermashnaya/VC-13) chlorogenic acid content increased 2-3 times compared to the content before low 
temperature stress. This is consistent with the hypothesis of N.V. Zagoskina (2005) regarding a more significant change in phenolic metabolism under the influence of stress in plants with low ability to synthesize them [19].

\section{Conclusions}

As a result of studies, the reproductive buds' frost resistance after freezing with critically low temperatures after mid-winter conditioning was identified for two sweet cherry varieties. In the Fatezh variety, the preservation of live floral rudiments amounted to over $80 \%$ and was significantly higher than that of the Chermashnaya variety (about $40 \%$ ). Influence of rootstock and limits of varieties' frost resistance change depending on the rootstock were shown: Fatezh variety - floral rudiments' preservation ranged from $62.2 \%$ (VSL-2) to $81.7 \%$ (Izmailovsky), and Chermashnaya variety — from $25.5 \%$ (P. magaleb L) to $65 \%$ (Izmailovsky).

When using winter-proof clone rootstocks Izmailovsky, AVCH-2 and Moskoviya, the floral rudiments' preservation in both varieties with freezing $\mathrm{t}=-29{ }^{\circ} \mathrm{C}$ after conditioning increased by $15-20 \%$ compared to seedling rootstock Prunus magaleb L.

The greatest frost resistance was characteristic to the scion/rootstock combinations of Fatezh/Izmailovsky and Fatezh/AVCH-2, which preserved more than $87 \%$ of live rudiments.

A strong positive correlation between the frost resistance of floral buds and the chlorogenic acid content in the buds prior to freezing was established. This indicator can serve as a marker in the study of sweet cherry winter resistance.

\section{Acknowledgments}

The authors thank the Non-profit Organization "Foundation for the Development and Support of Horticulture" for the financial support in the publication of the article.

\section{References}

1. M.V. Kanshina, Fruit growing and berry growing of Russia, 48(2), 130 (2017)

2. Z.E. Ozherelyeva, Scientific and methodical electronic journal Concept, 13, 161 (2015)

3. N.G. Morozova, G.Yu. Upadysheva, Horticulture and viticulture, 3, 17 (2014)

4. A.A. Gulyaeva, I.N. Efremov, T.N. Berlova, Modern horticulture, 4(24), 25 (2017)

5. A.A. Taranov, I.G. Polubyatko Breeding and cultivating of garden crops, 4(1-2),127 (2017)

6. V. Lichev, A. Papachatzis, SodininkysteirDarzininkust, 25(3), 296 (2006)

7. Dz. Dekena, I. Alsina,17th International Scientific Conference Proceedins, Elgava: LLU, 47 (2011)

8. V. Usenik, N. Fajt, M. Mikulic-Petkovsek, A. Slatnar, F. Stampar, R. Veberic, Journal of Agricultural and Food Chemistry, 58(8), 4928 (2010)

9. N.S. Kolpakov, G.Yu. Upadysheva, Fruit growing and berry growing of Russia, 16, 155 (2006)

10. N.A. Minaeva, G.Yu. Upadysheva, Fruit growing and berry growing in Russia, 31(2), 65 (2012)

11. N.S. Kolpakov, Fruit growing and berry growing of Russia, 18, 474 (2008) 
12. Z.E. Ozherelyeva, P.S. Prudnikov, I.N. Efremov, Herald of the Russian Agricultural Science, 4, 29 (2020)

13. Dz. Dekena, J. Lepsis, L. Lepse, I. Alsina, K. Kahu, Proceedings of the Latvian Academy of Sciences, Section B: Natural, Exact, and Applied Sciences, 73(3), 257 (2019)

14. M.T. Upadyshev, The role of phenolic compounds in life processes of garden plants (2008)

15. M.M. Tyurina, G.A. Gogoleva, N.V. Efimova et al, Stability determination of fruit and berry crops to stressors of the cold season in field and controlled conditions: methodological recommendations (2002)

16. V. Lichev, A. Papachatzis, Journal of the Agricultural University- Plovdiv, 1(2), 31 (2009)

17. G.Yu. Upadysheva, S.M. Motyleva, T.A. Tumaeva, M.E. Mertvishcheva, Horticulture and viticulture, 5, 47 (2019)

18. N.I. Nenko, I.A. Ilyina, V.S. Petrov, M.A. Sundyreva, T.V. Skhalyakho, Phenolic compounds: functional role in plants: proceedings of the X Intern. Symposium, 293 (2018)

19. N.V. Zagoskina Proceedings of the VI Inter. Symposium "New and Unconventional Plants and Prospects for Their Use", 3, 300 (2005) 